\title{
Recognition Of MRR And Surface Coarseness Values By Using Taguchi Method
}

\author{
PRASANNA P \\ Assistant professor, Dept of Mechanical, AVN \\ Institute of Engineering \& Technology, Hyderabad, \\ T.S., India.
}

\author{
HARISH HARSURKAR \\ Assistant professor, Dept of Mechanical, AVN \\ Institute of Engineering \& Technology, Hyderabad, \\ T.S., India.
}

RASURE SHANTH KUMAR

M. Tech student, Dept of Mechanical Engineering, AVN Institute of Engineering \& Technology, Hyderabad, T.S., India.

Abstract: Turning technique is one of the most important machining approaches used within the manufacturing employer. The technique of turning is stimulated via many factors including decreasing pace, feed price, the intensity of reducing, the geometry of reducing tool, and reducing situations and many others., to name a few. In machining operations, sporting out the favoured surface terrific of the machined product is really a difficult undertaking. This is because of the fact that excellent is pretty stimulated thru method parameters right now or in a roundabout way. The results received from the experiments are modified into signal-to-noise ratio(S/N) ratio and used to optimize the value of MRR and ground roughness. The ANOVA is performed to pick out the importance of parameters. The final consequences of experimental observations are provided in this paper. The conclusions arrived at are considerably referred to on the giving up. In this thesis, the effect of insert nose radius and machining parameters together with reducing tempo, feed charge and depth of lowering on ground roughness in a turning operation are investigated by way of way of the use of the Taguchi optimization approach. 3D modelling performed by using the use of the usage of CREO parametric software program. The analysis is done by the use of ANSYS.

Keywords: ANSYS, CREO, Taguchi Method, Terrific Values, Roughness, Parameters;

\section{INTRODUCTION:}

In steel reducing industries the maximum drawback isn't running the tool to their most high-quality working situations and the going for walks situations remains selected entirely on the concept of the manual values or operator's revel in. In metallic reducing industries turning is the majorly used gadget for doing away with the fabric from the cylindrical paintings piece. Turning is the removal of steel from the outer diameter of a rotating cylindrical workpiece. Turning is used to reduce the diameter of the artwork piece, usually to a special size, and to supply an easy finish on the metal. Often the workpiece may be grown to become so that adjacent sections have exceptional diameters. For longer workpieces we'd want to face and middle drill the unfastened surrender and use a dead or alive centre within the tailstock to resource it. Without this sort of manual, the pressure of the device on the workpiece might purpose it to bend far from the device, generating a surprisingly shaped result. There is also the ability that the paintings may be forced to loosen in the chuck jaws and fly out as a risky projectile. Insert the workpiece inside the three-jaw chuck and tighten down the jaws till they just begin to grip the workpiece. Rotate the workpiece to ensure that its miles seated flippantly and to dislodge any chips or grit at the ground that would maintain it from seating frivolously. You need the workpiece to be as parallel as feasible with the middle line of the lathe. Imagine an exaggerated instance wherein the workpiece is skewed at a perspective inside the chuck and you can without issues visualize why that is vital. Tighten the chuck the usage of each of the 3 chuck key positions to make certain a respectable or maybe grip.

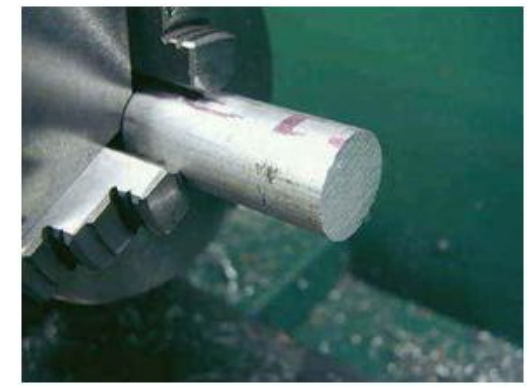

Fig.1.1. Model work piece.

Without shifting the bypass slide or compound, rotate the carriage hand wheel clockwise to transport the device lower back closer to the loose pinnacle of the paintings. You will look at that the tool gets rid of a small amount of steel on the return pass. Advance the go slides every other .010 and repeat this approach till you've got an extremely good feel for it. Try advancing the cross slide by .020 on one skip. You will experience that it takes greater pressure at the carriage hand wheel at the same time as you are taking a deeper reduce. 


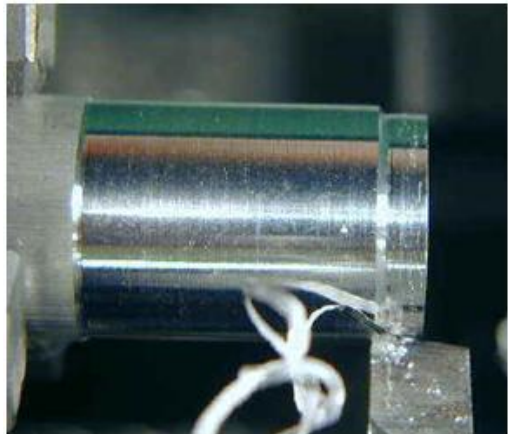

Fig.1.2. Turning with Hand Feed

2. RELATED STUDY:

Machining operations have been the middle of the producing organisation because of the reality the economic revolution and the prevailing optimization researches for Computer Numerical Controlled (CNC) turning had been each simulated indoors precise manufacturing situations or completed through several commonplace machine operations. These conditions or production Circumstances appear as computing simulations and their applicability to the real worldwide company continues to be uncertain and consequently, a big optimization scheme without device operations is deemed to be constantly advanced. Surface roughness is typically taken into consideration as a high manufacturing intention for turning operations in a maximum of the present researches. The machining method on a CNC lathe is programmed. Many floor roughness prediction structures have been designed with the usage of a selection of sensors inclusive of dynamometers for strain and torque. Taguchi and Analysis of Variance (ANOVA) can correctly optimize the lowering parameters with numerous experimental runs properly designed. The blessings of tuning of tough substances are higher productiveness, decreased installation instances, ground finish towards grinding and the ability to tool complex components. Rigid device equipment with proper enough strength, very difficult and difficult tool substances with appropriate tool geometry, tool holders with immoderate stiffness and appropriate slicing situations are a number of the situations for tough turning. Material Removal Rate (MRR) is a critical trouble to be considered within the hard turning of steels because it right away affects the machining time. It furthermore modified into cited that the following machining time discount is as immoderate as $60 \%$ in tough turning in comparison to the ground. Surface residences at the side of roughness are essential to the useful potential of tool additives. Increased information of the floor technology mechanisms can be used to optimize the machining approach and to decorate hassle feature capability.

\section{DESIGN AND METHODOLOGY:}

Computers are being used increasingly more for each layout and detailing of engineering components in the drawing workplace. Computeraided layout (CAD) is defined as the application of computer systems and snaps shots software to aid or decorate the product design from conceptualization to documentation. CAD is most commonly related to using an interactive pc snap shots device, referred to as a CAD gadget. Computer-aided design structures are powerful gear and inside the mechanical format and geometric modelling of merchandise and additives. There are several appropriate motives for using a $\mathrm{CAD}$ gadget to help the engineering format

Companies use Pro/ENGINEER to create a whole three-D digital model in their merchandise. The fashions embody 2D and three-d stable version information which can also be used downstream infinite element assessment, speedy prototyping, tooling format, and CNC manufacturing. All data are associative and interchangeable between the $\mathrm{CAD}, \mathrm{CAE}$ and CAM modules without conversion. A product and its whole invoice of materials (BOM) can be modelled because it must be with definitely associative engineering drawings, and revision manipulates information. The associatively in Pro/ENGINEER lets in customers to make modifications inside the design at any time in the route of the product improvement approach and routinely update downstream deliverables.

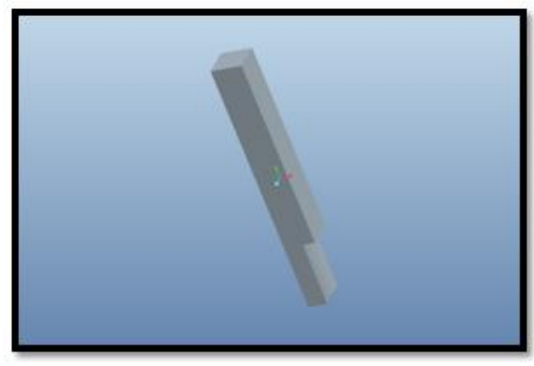

Fig.3.1. 3D cutting tool.

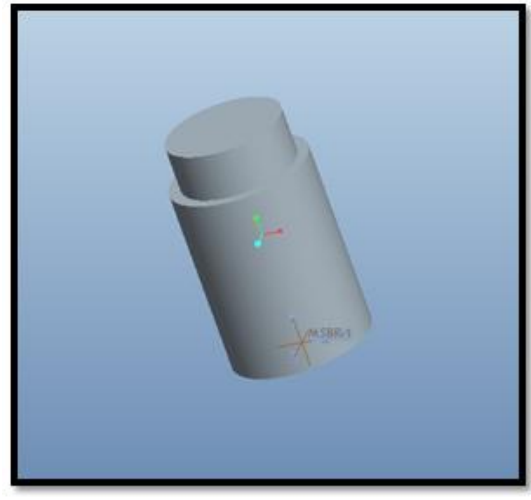

Fig.3.2. 3D model of work piece. 


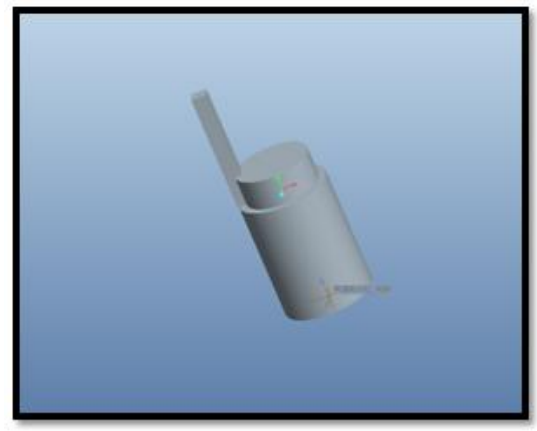

Fig.3.3. Assembly model.

\section{CUTTING FORCES AND SURFACE FINISH:}

Knowing the fee of the lowering forces inside the turning process as a feature of the parameters and conditions of treatment is essential for determining of reducing device energy, contemporary sporting, restriction of the maximum load of the reducing gadget and forecasting the predicted effects of the processing. In specific, all through machining with immoderate reducing speed, the use of modern-day substances and modern lowering machines imposes the need of analyzing physical phenomena within the slicing method and their mathematical modeling.
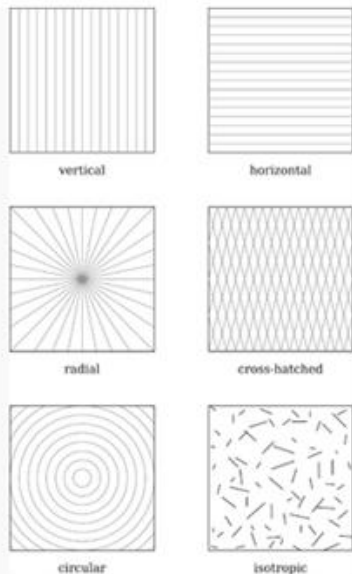

Fig.3.4. Examples of various lay patterns.

4. EXPERIMENTAL INVESTIGATION RESULTS:

The experiments are done on the CNC turning machine with the following parameters:

CUTTING TOOL MATERIAL -cemented Carbide Tool

WORK PIECE MATERIAL - EN 31Tool Steel

FEED $-200 \mathrm{~mm} / \mathrm{min}, 250 \mathrm{~mm} / \mathrm{min}, 300 \mathrm{~mm} / \mathrm{min}$

CUTTING SPEED - 600rpm, 1200rpm, 1800rpm, DEPTH OF CUT $-0.4 \mathrm{~mm}, 0.5 \mathrm{~mm}, 0.6 \mathrm{~mm}$.

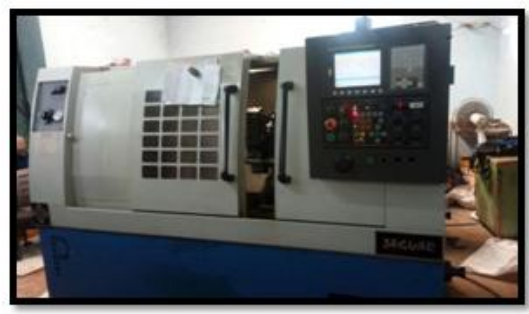

Fig.4.1. CNC machine.

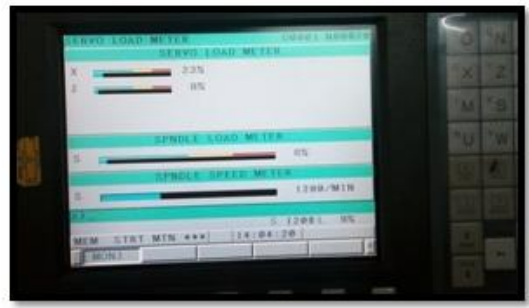

Fig.4.2. Input Parameters.

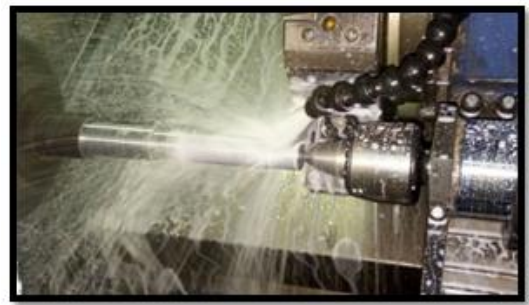

Fig.4.3. Working condition.

Taguchi defines Quality Level of a product as the Total Loss incurred with the aid of society because of the failure of a product to carry out as favored while it deviates from the added target overall performance stages. This includes charges related to bad performance, working prices (which adjustments as a product age) and any introduced charges due to dangerous side results of the product in use. In order to find out the technique parameters affecting the selected tool exceptional characteristics of turning, the following method parameters are selected for the winning artwork: lowering velocity (A), feed fee (B) and intensity of reducing $(\mathrm{C})$. The preference of parameters of interest and their levels is based totally on literature evaluation and some preliminary experiments executed.

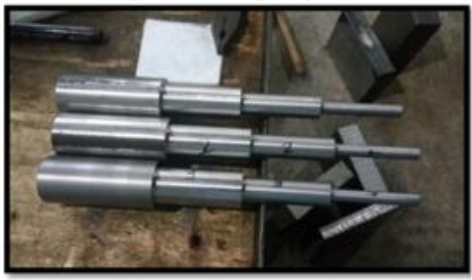

Fig.4.4. Final work pieces.

Selection of Orthogonal Array:

The device parameters and their values are given in desk. It turns into additionally determined to observe the two - hassle interplay results of way parameters on the chosen inclinations on the same 
time as turning. These interactions were taken into consideration amongst decreasing the pace and feed rate $(\mathrm{AXB})$, feed price and intensity of lessen (BXC), slicing pace and intensity of lessen (AXC).

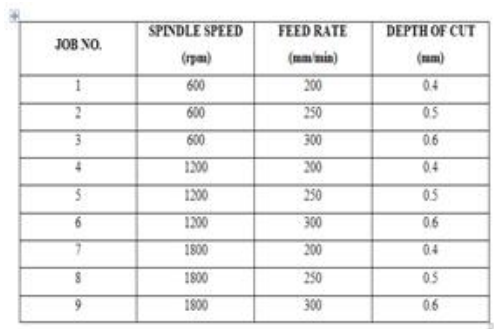

Fig.4.5. TAGUCHI ORTHOGONAL ARRAY.

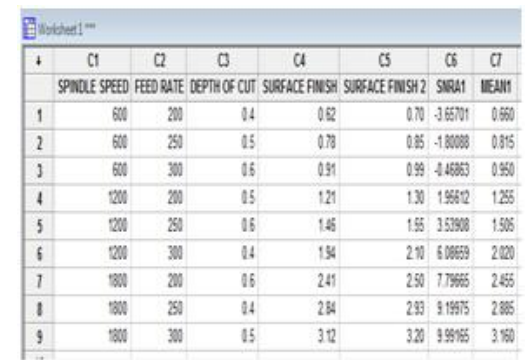

Fig.4.6. Output results.

\section{CONCLUSION:}

The reducing parameters are lowering pace, feed fee and depth of lessen for turning of workpiece EN 31 device steel. In this art work, the closing parameters of reducing pace are 600rpm, $1200 \mathrm{rpm}$ and $1800 \mathrm{rpm}$, feed fee is $200 \mathrm{~mm} / \mathrm{min}, 250 \mathrm{~mm} / \mathrm{min}$ and $300 \mathrm{~mm} / \mathrm{min}$ and depth of reduce are zero. $4 \mathrm{~mm}$, zero. $5 \mathrm{~mm}$, and zero. $6 \mathrm{~mm}$. Experimental paintings are finished via thinking about the above parameters. Cutting forces, floor surrender and reducing temperatures are tested experimentally. By searching on the experimental results and through using the usage of Taguchi, the subsequent conclusions can be made: To lessen the slicing forces, the most reliable parameters are spindle pace $-600 \mathrm{rpm}$, feed price $-200 \mathrm{~mm} / \mathrm{min}$ and depth of reduce $-0.4 \mathrm{~mm}$. To get the higher ground prevent, the most beneficial parameters are spindle pace $-1800 \mathrm{rpm}$, feed rate $-300 \mathrm{~mm} / \mathrm{min}$ and intensity of lessen - zero. $6 \mathrm{~mm}$. To maximize fabric removal charge, the excellent parameters are spindle tempo $-600 \mathrm{rpm}$, feed rate $-200 \mathrm{~mm} / \mathrm{min}$ and intensity of reduce - zero. $6 \mathrm{~mm}$. The outcomes of these parameters at the lowering forces have calculated the usage of theoretical calculations and using the forces stresses and displacements are analyzed the use of Ansys. Three-d modeling is completed in Pro/Engineer. By looking on the evaluation results, the stress values are much less than the yield strains values.

\section{REFERENCES:}

[1] Grzesik, W., Wanat, T. Surface quit generated in hard turning of quenched alloy steel components the usage of conventional and wiper ceramic inserts, International Journal of Machine Tools and Manufacture, vol. Forty six, 2006,1988-1995.

[2] Siler, H.R., Vila, C., Rodríguez, C.A., Abellán, J.V. (2009). Study of face milling of hardened AISI d3 metal with a completely unique layout of carbide tools, Int J. Adv. Manuf. Technol., vol. Forty, 1225 .

[3] Tonshoff HK, Wobker HG,Brandt D. Tool put on and ground integrity in difficult turning,ProductionEngineering, 3(1),1996,19-24.

[4] Ali Riza Motorcu The Optimization of Machining Parameters Using the Taguchi Method for Surface Roughness of AISI 8660 Hardened Alloy Steel,Journal of Mechanical Engineering, 2010, 391-401.

[5] Tonshoff HK,Wobker HG,Brandt D. Hardturning-Influence at the workpiece homes, Trans NAMRI/SME, 1995,215- 220.

[6]. Analyses of floor roughness through turning technique using Taguchi method with the useful resource of manner of $\mathrm{S}$. Thamizhmanii, S. Saparudin, S. Hasan

[7]. Application of Taguchi Method for Optimizing Turning Process through the outcomes of Machining Parameters with the resource of Krishankant, JatinTaneja, MohitBector, Rajesh Kumar.

[8]. Multi-Objective Optimization of the Cutting Forces in Turning Operations Using the Grey-Based Taguchi Method with the aid of the use of Yigit 